\title{
A strong convergence theorem for solutions of equilibrium problems and asymptotically quasi- $\phi$-nonexpansive mappings in the intermediate sense
}

Yuan Qing ${ }^{1}$ and Songtao LV ${ }^{2 *}$

"Correspondence: sqlvst@yeah.net ${ }^{2}$ School of Mathematics and Information Science, Shangqiu Normal University, Shangqiu, 476000, China

Full list of author information is available at the end of the article

\begin{abstract}
In this paper, common solutions to an equilibrium problem and a nonlinear operator equation involving a finite family of asymptotically quasi- $\phi$-nonexpansive mappings in the intermediate sense are discussed. Strong convergence theorems of common solutions are established in a uniformly smooth and strictly convex Banach space which also enjoys the Kadec-Klee property.

MSC: 47H09; 47J25

Keywords: asymptotically quasi- $\phi$-nonexpansive mapping; asymptotically quasi- $\phi$-nonexpansive mapping in the intermediate sense; generalized projection; equilibrium problem; fixed point
\end{abstract}

\section{Introduction}

Equilibrium problems have been revealed as a very powerful and important tool in the study of nonlinear phenomena. They have turned out to be very useful in studying optimization problems, differential equations, and minimax theorems and in certain applications to mechanics and economic theory; see [1-27] and the references therein. Important practical situations motivate the study of a system of equilibrium problems. For instance, the flow of fluid through a fissured porous medium and certain models of plasticity led to such problems; see, for instance, [28]. Because of their importance, they have been extensively analyzed. The aim of this paper is to present an iterative method for solving solutions of an equilibrium problem, which is known as the Ky Fan inequality, and a nonlinear operator equation involving a finite family of asymptotically quasi- $\phi$-nonexpansive mappings in the intermediate sense.

The organization of this paper is as follows. In Section 2, we provide some necessary preliminaries. In Section 3, an iterative algorithm is presented. A strong convergence theorem is established in a reflexive Banach space. Some results in Hilbert spaces are also discussed.

\section{Preliminaries}

Let $E$ be a real Banach space. Recall that the normalized duality mapping $J$ from $E$ to $2^{E^{*}}$ is defined by

$$
J x=\left\{f^{*} \in E^{*}:\left\langle x, f^{*}\right\rangle=\|x\|^{2}=\left\|f^{*}\right\|^{2}\right\},
$$

○2013 Qing and Lv; licensee Springer. This is an Open Access article distributed under the terms of the Creative Commons Attribution License (http://creativecommons.org/licenses/by/2.0), which permits unrestricted use, distribution, and reproduction in any medium, provided the original work is properly cited. 
where $\langle\cdot, \cdot\rangle$ denotes the generalized duality pairing. Recall that $E$ is said to be strictly convex if $\left\|\frac{x+y}{2}\right\|<1$ for all $x, y \in E$ with $\|x\|=\|y\|=1$ and $x \neq y$. It is said to be uniformly convex if $\lim _{n \rightarrow \infty}\left\|x_{n}-y_{n}\right\|=0$ for any two sequences $\left\{x_{n}\right\}$ and $\left\{y_{n}\right\}$ in $E$ such that $\left\|x_{n}\right\|=\left\|y_{n}\right\|=1$ and $\lim _{n \rightarrow \infty}\left\|\frac{x_{n}+y_{n}}{2}\right\|=1$. Let $U_{E}=\{x \in E:\|x\|=1\}$ be the unit sphere of $E$. Then the Banach space $E$ is said to be smooth if $\lim _{t \rightarrow 0} \frac{\|x+t y\|-\|x\|}{t}$ exists for each $x, y \in U_{E}$. It is said to be uniformly smooth if the above limit is attained uniformly for $x, y \in U_{E}$. It is well known that if $E$ is uniformly smooth, then $J$ is uniformly norm-to-norm continuous on each bounded subset of $E$. It is also well known that if $E$ is uniformly smooth if and only if $E^{*}$ is uniformly convex.

Recall that $E$ enjoys the Kadec-Klee property if for any sequence $\left\{x_{n}\right\} \subset E$, and $x \in E$ with $x_{n} \rightarrow x$, and $\left\|x_{n}\right\| \rightarrow\|x\|$, then $\left\|x_{n}-x\right\| \rightarrow 0$ as $n \rightarrow \infty$. It is well known that if $E$ is a uniformly convex Banach space, then $E$ enjoys the Kadec-Klee property.

Next, we assume that $E$ is a smooth Banach space. Consider the functional defined by

$$
\phi(x, y)=\|x\|^{2}-2\langle x, J y\rangle+\|y\|^{2}, \quad \forall x, y \in E .
$$

Observe that in a Hilbert space $H$, the equality is reduced to $\phi(x, y)=\|x-y\|^{2}, x, y \in H$. As we all know, if $C$ is a nonempty closed convex subset of a Hilbert space $H$ and $P_{C}: H \rightarrow C$ is the metric projection of $H$ onto $C$, then $P_{C}$ is nonexpansive. This fact actually characterizes Hilbert spaces and, consequently, it is not available in more general Banach spaces. In this connection, Alber [29] recently introduced a generalized projection operator $\Pi_{C}$ in a Banach space $E$ which is an analogue of the metric projection $P_{C}$ in Hilbert spaces. Recall that the generalized projection $\Pi_{C}: E \rightarrow C$ is a map that assigns to an arbitrary point $x \in E$ the minimum point of the functional $\phi(x, y)$, that is, $\Pi_{C} x=\bar{x}$, where $\bar{x}$ is the solution to the minimization problem

$$
\phi(\bar{x}, x)=\min _{y \in C} \phi(y, x)
$$

Existence and uniqueness of the operator $\Pi_{C}$ follows from the properties of the functional $\phi(x, y)$ and strict monotonicity of the mapping $J$. In Hilbert spaces, $\Pi_{C}=P_{C}$. It is obvious from the definition of function $\phi$ that

$$
(\|x\|-\|y\|)^{2} \leq \phi(x, y) \leq(\|y\|+\|x\|)^{2}, \quad \forall x, y \in E
$$

and

$$
\phi(x, y)=\phi(x, z)+\phi(z, y)+2\langle x-z, J z-J y\rangle, \quad \forall x, y, z \in E .
$$

Remark 2.1 If $E$ is a reflexive, strictly convex and smooth Banach space, then $\phi(x, y)=0$ if and only if $x=y$; for more details, see [29] and the reference therein.

Let $f$ be a bifunction from $C \times C$ to $\mathbb{R}$, where $\mathbb{R}$ denotes the set of real numbers and let $A: C \rightarrow E^{*}$ be a mapping. Consider the following equilibrium problem. Find $p \in C$ such that

$$
f(p, q)+\langle A p, q-p\rangle \geq 0, \quad \forall q \in C .
$$


We use $E P(f, A)$ to denote the solution set of inequality (2.3). That is,

$$
E P(f)=\{p \in C: f(p, q)+\langle A p, q-p\rangle \geq 0, \forall q \in C\} .
$$

If $A=0$, then problem (2.3) is reduced to the following Ky Fan inequality. Find $p \in C$ such that

$$
f(p, q) \geq 0, \quad \forall q \in C .
$$

We use $E P(f)$ to denote the solution set of inequality (2.4). That is,

$$
E P(f)=\{p \in C: f(p, q) \geq 0, \forall q \in C\} .
$$

If $f=0$, then problem (2.3) is reduced to the classical variational inequality. Find $p \in C$ such that

$$
\langle A p, q-p\rangle \geq 0, \quad \forall q \in C
$$

We use $\operatorname{VI}(C, A)$ to denote the solution set of inequality (2.5). That is,

$$
V I(C, A)=\{p \in C:\langle A p, q-p\rangle \geq 0, \forall q \in C\} .
$$

Recall that a mapping $A: C \rightarrow E^{*}$ is said to be $\alpha$-inverse-strongly monotone if there exists $\alpha>0$ such that

$$
\langle A x-A y, x-y\rangle \geq \alpha\|A x-A y\|^{2} .
$$

For solving problem (2.3), let us assume that the nonlinear mapping $A: C \rightarrow E^{*}$ is $\alpha$-inverse-strongly monotone and the bifunction $f: C \times C \rightarrow \mathbb{R}$ satisfies the following conditions:

(A1) $F(x, x)=0, \forall x \in C$;

(A2) $F$ is monotone, i.e., $F(x, y)+F(y, x) \leq 0, \forall x, y \in C$;

(A3)

$$
\limsup _{t \downarrow 0} F(t z+(1-t) x, y) \leq F(x, y), \quad \forall x, y, z \in C ;
$$

(A4) for each $x \in C, y \mapsto F(x, y)$ is convex and weakly lower semi-continuous.

Let $C$ be a nonempty subset of $E$ and $T: C \rightarrow C$ be a mapping. In this paper, we use $F(T)$ to denote the fixed point set of $T . T$ is said to be asymptotically regular on $C$ if for any bounded subset $K$ of $C$,

$$
\limsup _{n \rightarrow \infty}\left\{\left\|T^{n+1} x-T^{n} x\right\|: x \in K\right\}=0 .
$$

$T$ is said to be closed if for any sequence $\left\{x_{n}\right\} \subset C$ such that $\lim _{n \rightarrow \infty} x_{n}=x_{0}$ and $\lim _{n \rightarrow \infty} T x_{n}=y_{0}$, then $T x_{0}=y_{0}$. In this paper, we use $\rightarrow$ and $\rightarrow$ to denote the strong convergence and weak convergence, respectively. 
Recall that a point $p$ in $C$ is said to be an asymptotic fixed point of $T$ iff $C$ contains a sequence $\left\{x_{n}\right\}$ which converges weakly to $p$ such that $\lim _{n \rightarrow \infty}\left\|x_{n}-T x_{n}\right\|=0$. The set of asymptotic fixed points of $T$ will be denoted by $\widetilde{F}(T)$.

A mapping $T$ is said to be relatively nonexpansive iff

$$
\widetilde{F}(T)=F(T) \neq \emptyset, \quad \phi(p, T x) \leq \phi(p, x), \quad \forall x \in C, \forall p \in F(T) .
$$

A mapping $T$ is said to be relatively asymptotically nonexpansive iff

$$
\widetilde{F}(T)=F(T) \neq \emptyset, \quad \phi\left(p, T^{n} x\right) \leq\left(1+\mu_{n}\right) \phi(p, x), \quad \forall x \in C, \forall p \in F(T), \forall n \geq 1,
$$

where $\left\{\mu_{n}\right\} \subset[0, \infty)$ is a sequence such that $\mu_{n} \rightarrow 0$ as $n \rightarrow \infty$.

Remark 2.2 The class of relatively asymptotically nonexpansive mappings was first considered in Agarwal et al. [30].

Recall that a mapping $T$ is said to be quasi- $\phi$-nonexpansive iff

$$
F(T) \neq \emptyset, \quad \phi(p, T x) \leq \phi(p, x), \quad \forall x \in C, \forall p \in F(T) .
$$

Recall that a mapping $T$ is said to be asymptotically quasi- $\phi$-nonexpansive iff there exists a sequence $\left\{\mu_{n}\right\} \subset[0, \infty)$ with $\mu_{n} \rightarrow 0$ as $n \rightarrow \infty$ such that

$$
F(T) \neq \emptyset, \quad \phi\left(p, T^{n} x\right) \leq\left(1+\mu_{n}\right) \phi(p, x), \quad \forall x \in C, \forall p \in F(T), \forall n \geq 1 .
$$

Remark 2.3 The class of quasi- $\phi$-nonexpansive mappings and the class of asymptotically quasi- $\phi$-nonexpansive mappings are more general than the class of relatively nonexpansive mappings and the class of relatively asymptotically nonexpansive mappings. Quasi$\phi$-nonexpansive mappings and asymptotically quasi- $\phi$-nonexpansive mappings do not require the restriction $F(T)=\widetilde{F}(T)$; for more details, see [31-33] the reference therein.

Remark 2.4 The class of quasi- $\phi$-nonexpansive mappings and the class of asymptotically quasi- $\phi$-nonexpansive mappings are generalizations of the class of quasi-nonexpansive mappings and the class of asymptotically quasi-nonexpansive mappings in Banach spaces.

Recall that $T$ is said to be asymptotically quasi- $\phi$-nonexpansive in the intermediate sense iff $F(T) \neq \emptyset$ and the following inequality holds:

$$
\limsup _{n \rightarrow \infty} \sup _{p \in F(T), x \in C}\left(\phi\left(p, T^{n} x\right)-\phi(p, x)\right) \leq 0 .
$$

Put

$$
\xi_{n}=\max \left\{0, \sup _{p \in F(T), x \in C}\left(\phi\left(p, T^{n} x\right)-\phi(p, x)\right)\right\} .
$$

It follows that $\xi_{n} \rightarrow 0$ as $n \rightarrow \infty$. Then (2.6) is reduced to the following:

$$
\phi\left(p, T^{n} x\right) \leq \phi(p, x)+\xi_{n}, \quad \forall p \in F(T), \forall x \in C .
$$


Remark 2.5 The class of asymptotically quasi- $\phi$-nonexpansive mappings in the intermediate sense was first considered by Qin and Wang [34]; see also [35].

Remark 2.6 The class of asymptotically quasi- $\phi$-nonexpansive mappings in the intermediate sense is a generalization of the class of asymptotically quasi-nonexpansive mappings in the intermediate sense, which was considered by Kirk [36] in the framework of Banach spaces.

In order to state our main results, we also need the following lemmas.

Lemma 2.7 [29] Let $C$ be a nonempty closed convex subset of a smooth Banach space $E$ and $x \in E$. Then $x_{0}=\Pi_{C} x$ if and only if

$$
\left\langle x_{0}-y, J x-J x_{0}\right\rangle \geq 0, \quad \forall y \in C .
$$

Lemma 2.8 [29] Let E be a reflexive, strictly convex, and smooth Banach space, let $C$ be a nonempty closed convex subset of $E$ and $x \in E$. Then

$$
\phi\left(y, \Pi_{C} x\right)+\phi\left(\Pi_{C} x, x\right) \leq \phi(y, x), \quad \forall y \in C .
$$

Lemma 2.9 [37] Let E be a smooth, strictly convex, and reflexive Banach space, and let $C$ be a nonempty closed convex subset of $E$. Let $A: C \rightarrow E^{*}$ be an $\alpha$-inverse-strongly monotone mapping and $f$ be a bifunction satisfying conditions (A1)-(A4). Let $r>0$ be any given number, and let $x \in E$ define a mapping $K_{r}: C \rightarrow C$ as follows: for any $x \in C$,

$$
K_{r} x=\left\{p \in C: f(p, q)+\langle A p, q-p\rangle+\frac{1}{r}\langle q-p, J p-J x\rangle \geq 0\right\}, \quad \forall q \in C .
$$

Then the following conclusions hold:

(1) $K_{r}$ is single-valued;

(2) $K_{r}$ is a firmly nonexpansive-type mapping, i.e., for all $x, y \in E$,

$$
\left\langle K_{r} x-K_{r} y, J K_{r} x-J K_{r} y\right\rangle \leq\left\langle S_{r} x-S_{r} y, J x-J y\right\rangle
$$

(3) $F\left(K_{r}\right)=E P(f, A)$;

(4) $K_{r}$ is quasi- $\phi$-nonexpansive;

(5)

$$
\phi\left(q, K_{r} x\right)+\phi\left(K_{r} x, x\right) \leq \phi(q, x), \quad \forall q \in F\left(K_{r}\right)
$$

(6) $E P(f, A)$ is closed and convex.

Lemma 2.10 [38] Let E be a smooth and uniformly convex Banach space, and let $r>0$. Then there exists a strictly increasing, continuous, and convex function $g:[0,2 r] \rightarrow R$ such that $g(0)=0$ and

$$
\|t x+(1-t) y\|^{2} \leq t\|x\|^{2}+(1-t)\|y\|^{2}-t(1-t) g(\|x-y\|)
$$

for all $x, y \in B_{r}=\{x \in E:\|x\| \leq r\}$ and $t \in[0,1]$. 


\section{Main results}

Theorem 3.1 Let E be a uniformly smooth and strictly convex Banach space which also enjoys the Kadec-Klee property, and let $C$ be a nonempty closed and convex subset of E. Let $f$ be a bifunction from $C \times C$ to $\mathbb{R}$ satisfying (A1)-(A4), and let $N$ be some positive integer. Let $A: C \rightarrow E^{*}$ be a $\kappa_{i}$-inverse-strongly monotone mapping. Let $T_{i}: C \rightarrow C$ be an asymptotically quasi- $\phi$-nonexpansive mapping in the intermediate sense for every $1 \leq i \leq N$. Assume that $T_{i}$ is closed asymptotically regular on $C$ and $\bigcap_{i=1}^{N} F\left(T_{i}\right) \cap E P(f, A)$ is nonempty and bounded. Let $\left\{x_{n}\right\}$ be a sequence generated in the following manner:

$$
\left\{\begin{array}{l}
x_{0} \in C \quad \text { chosen arbitrarily, } \\
y_{n}=J^{-1}\left(\alpha_{n, 0} J x_{n}+\sum_{i=1}^{N} \alpha_{n, i} J T_{i}^{n} x_{n}\right), \\
u_{n} \in C \text { such that } f\left(u_{n}, y\right)+\left\langle A u_{n}+y-u_{n}\right\rangle+\frac{1}{r_{n}}\left\langle y-u_{n}, J u_{n}-J y_{n}\right\rangle \geq 0, \quad \forall y \in C, \\
H_{n}=\left\{z \in C: \phi\left(z, u_{n}\right) \leq \phi\left(z, x_{n}\right)+N \xi_{n}\right\}, \\
W_{n}=\left\{z \in C:\left\langle x_{n}-z, J x_{0}-J x_{n}\right\rangle \geq 0\right\}, \\
x_{n+1}=\Pi_{H_{n} \cap W_{n}} x_{0},
\end{array}\right.
$$

where $\xi_{n}=\max \left\{0, \sup _{p \in \bigcap_{i=1}^{N} F\left(T_{i}\right), x \in C}\left(\phi\left(p, T_{i}^{n} x\right)-\phi(p, x)\right)\right\},\left\{\alpha_{n, i}\right\}$ is a real number sequence in $(0,1)$ for every $1 \leq i \leq N,\left\{r_{n}\right\}$ is a real number sequence in $[k, \infty)$, where $k$ is some positive real number. Assume that $\sum_{i=0}^{N} \alpha_{n, i}=1$ and $\liminf _{n \rightarrow \infty} \alpha_{n, 0} \alpha_{n, i}>0$ for every $1 \leq i \leq N$. Then the sequence $\left\{x_{n}\right\}$ converges strongly to $\prod_{\bigcap_{i=1}^{N} F\left(T_{i}\right) \cap E P(f, A)} x_{0}$, where $\prod_{\bigcap_{i=1}^{N} F\left(T_{i}\right) \cap E P(f, A)}$ is the generalized projection from $E$ onto $\bigcap_{i=1}^{N} F\left(T_{i}\right) \cap E P(f, A)$.

Proof Since $F_{i}$ is closed and convex for every $1 \leq i \leq N$, we obtain from Lemma 2.9 that the common element set $\bigcap_{i=1}^{N} F\left(T_{i}\right) \cap E P(f, A)$ is closed and convex. Next, we show that both $H_{n}$ and $W_{n}$ are closed and convex. From the definition of $H_{n}$ and $W_{n}$, it is obvious that $H_{n}$ is closed and $W_{n}$ is closed and convex. We show that $H_{n}$ is convex since $\phi\left(z, u_{n}\right) \leq$ $\phi\left(z, x_{n}\right)+N \xi_{n}$ is equivalent to

$$
2\left\langle z, J x_{n}-J u_{n}\right\rangle \leq\left\|x_{n}\right\|^{2}-\left\|u_{n}\right\|^{2}+N \xi_{n}
$$

It follows that $H_{n}$ is convex. This in turn shows that $\Pi_{H_{n} \cap W_{n}} x_{0}$ is well defined. Putting $u_{n}=k_{r_{n}} y_{n}$, from Lemma 2.9 we see that $K_{r_{n}}$ is quasi- $\phi$-nonexpansive. Now, we are in a position to prove that $\bigcap_{i=1}^{N} F\left(T_{i}\right) \cap E P(f, A) \subset H_{n} \cap W_{n}$. Let $w \in \bigcap_{i=1}^{N} F\left(T_{i}\right) \cap E P(f, A)$,

$$
\begin{aligned}
\phi\left(w, u_{n}\right) & =\phi\left(w, K_{r_{n}} y_{n}\right) \\
& \leq \phi\left(w, y_{n}\right) \\
& =\phi\left(w, J^{-1}\left(\alpha_{n, 0} J x_{n}+\sum_{i=1}^{N} \alpha_{n, i} J T_{i}^{n} x_{n}\right)\right) \\
& =\|w\|^{2}-2\left\langle w, \alpha_{h, 0} J x_{n}+\sum_{i=1}^{N} \alpha_{n, i} J T_{i}^{n} x_{n}\right\rangle+\left\|\alpha_{n, 0} J x_{n}+\sum_{i=1}^{N} \alpha_{n, i} J T_{i}^{n} x_{n}\right\|^{2} \\
& \leq\|w\|^{2}-2 \alpha_{n, 0}\left\langle w, J x_{n}\right\rangle-2 \sum_{i=1}^{N} \alpha_{n, i}\left\langle w, J T_{i}^{n} x_{n}\right\rangle+\alpha_{n, 0}\left\|x_{n}\right\|^{2}+\sum_{i=1}^{N} \alpha_{n, i}\left\|T_{i}^{n} x_{n}\right\|^{2}
\end{aligned}
$$




$$
\begin{aligned}
& =\alpha_{n, 0} \phi\left(w, x_{n}\right)+\sum_{i=1}^{N} \alpha_{n, i} \phi\left(w, T_{i}^{n} x_{n}\right) \\
& \leq \alpha_{n, 0} \phi\left(w, x_{n}\right)+\sum_{i=1}^{N} \alpha_{n, i} \phi\left(w, x_{n}\right)+\sum_{i=1}^{N} \alpha_{n, i} \xi_{n} \\
& =\phi\left(w, x_{n}\right)+\sum_{i=1}^{N} \alpha_{n, i} \xi_{n} \\
& \leq \phi\left(w, x_{n}\right)+N \xi_{n} .
\end{aligned}
$$

We have $w \in H_{n}$. This implies that $\bigcap_{i=1}^{N} F\left(T_{i}\right) \cap E P(f, A) \subset H_{n}$. On the other hand, we see that $\bigcap_{i=1}^{N} F\left(T_{i}\right) \cap E P(f, A) \subset H_{0} \cap W_{0}$. Suppose that $\bigcap_{i=1}^{N} F\left(T_{i}\right) \cap E P(f, A) \subset H_{m} \cap W_{m}$ for some $m$. There exists an element $x_{m+1} \in H_{m} \cap W_{m}$ such that $x_{m+1}=\Pi_{H_{m} \cap W_{m}} x_{0}$. In view of Lemma 2.7, we find that

$$
\left\langle x_{m+1}-w, J x_{0}-J x_{m+1}\right\rangle \geq 0, \quad w \in H_{m} \cap W_{m} .
$$

Since $\bigcap_{i=1}^{N} F\left(T_{i}\right) \cap E P(f, A) \subset H_{m} \cap W_{m}$, we arrive at

$$
\left\langle x_{m+1}-w, J x_{0}-J x_{m+1}\right\rangle \geq 0
$$

for every $w \in \bigcap_{i=1}^{N} F\left(T_{i}\right) \cap E P(f, A)$. We therefore find that $\bigcap_{i=1}^{N} F\left(T_{i}\right) \cap E P(f, A) \subset W_{m+1}$. It follows that $\bigcap_{i=1}^{N} F\left(T_{i}\right) \cap E P(f, A) \subset H_{m+1} \cap W_{m+1}$. This shows that the sequence $\left\{x_{n}\right\}$ is well defined.

Next, we prove that the sequence $\left\{x_{n}\right\}$ is bounded. It follows from the definition of $W_{n}$ and Lemma 2.7 that $x_{n}=\Pi_{W_{n}} x_{0}$. In view of Lemma 2.8, we find that

$$
\phi\left(x_{n}, x_{0}\right)=\phi\left(\Pi_{W_{n}} x_{0}, x_{0}\right) \leq \phi\left(w, x_{0}\right)-\phi\left(w, x_{n}\right) \leq \phi\left(w, x_{0}\right)
$$

for each $w \in \bigcap_{i=1}^{N} F\left(T_{i}\right) \cap E P(f, A) \subset W_{n}$. This implies that $\left\{\phi\left(x_{n}, x_{0}\right)\right\}$ is bounded. It follows from (2.1) that $\left\{x_{n}\right\}$ is also bounded. Since $x_{n+1}=\Pi_{H_{n} \cap W_{n}} x_{0} \in W_{n}$, we find from Lemma 2.7 that $\phi\left(x_{n}, x_{0}\right) \leq \phi\left(x_{n+1}, x_{0}\right)$. Therefore, we obtain that $\left\{\phi\left(x_{n}, x_{0}\right)\right\}$ is nondecreasing. So there exists the limit of $\phi\left(x_{n}, x_{0}\right)$. It follows from Lemma 2.8 that

$$
\begin{aligned}
\phi\left(x_{n+1}, x_{n}\right) & =\phi\left(x_{n+1}, \Pi_{W_{n}} x_{0}\right) \\
& \leq \phi\left(x_{n+1}, x_{0}\right)-\phi\left(\Pi_{W_{n}} x_{0}, x_{0}\right) \\
& =\phi\left(x_{n+1}, x_{0}\right)-\phi\left(x_{n}, x_{0}\right) .
\end{aligned}
$$

This shows that $\lim _{n \rightarrow \infty} \phi\left(x_{n+1}, x_{n}\right)=0$. Since $x_{n+1}=\Pi_{H_{n} \cap W_{n}} x_{0} \in H_{n}$, we find that $\lim _{n \rightarrow \infty} \phi\left(x_{n+1}, u_{n}\right)=0$. Since the space is reflexive, we may assume, without loss of generality, that $x_{n} \rightarrow \bar{x}$. Since $W_{n}$ is closed and convex, we find that $\bar{x} \in W_{n}$. This implies from $x_{n}=\Pi_{W_{n}} x_{0}$ that $\phi\left(x_{n}, x_{0}\right) \leq \phi\left(\bar{x}, x_{0}\right)$. On the other hand, we see from the weakly lower semicontinuity of $\|\cdot\|$ that

$$
\begin{aligned}
\phi\left(\bar{x}, x_{0}\right) & =\|\bar{x}\|^{2}-2\left\langle\bar{x}, J x_{0}\right\rangle+\left\|x_{0}\right\|^{2} \\
& \leq \liminf _{n \rightarrow \infty}\left(\left\|x_{n}\right\|^{2}-2\left\langle x_{n}, J x_{0}\right\rangle+\left\|x_{0}\right\|^{2}\right)
\end{aligned}
$$




$$
\begin{aligned}
& =\liminf _{n \rightarrow \infty} \phi\left(x_{n}, x_{0}\right) \\
& \leq \limsup _{n \rightarrow \infty} \phi\left(x_{n}, x_{0}\right) \\
& \leq \phi\left(\bar{x}, x_{0}\right),
\end{aligned}
$$

which implies that $\lim _{n \rightarrow \infty} \phi\left(x_{n}, x_{0}\right)=\phi\left(\bar{x}, x_{0}\right)$. Hence, we have $\lim _{n \rightarrow \infty}\left\|x_{n}\right\|=\|\bar{x}\|$. In view of the Kadec-Klee property of $E$, we find that $x_{n} \rightarrow \bar{x}$ as $n \rightarrow \infty$. In view of (2.1), we see that $\lim _{n \rightarrow \infty}\left(\left\|x_{n+1}\right\|-\left\|u_{n}\right\|\right)=0$. This implies that $\lim _{n \rightarrow \infty}\left\|u_{n}\right\|=\|\bar{x}\|$. That is,

$$
\lim _{n \rightarrow \infty}\left\|J u_{n}\right\|=\lim _{n \rightarrow \infty}\left\|u_{n}\right\|=\|J \bar{x}\|
$$

This implies that $\left\{J u_{n}\right\}$ is bounded. Note that both $E$ and $E^{*}$ are reflexive. We may assume, without loss of generality, that $J u_{n} \rightarrow u^{*} \in E^{*}$. In view of the reflexivity of $E$, we see that $J(E)=E^{*}$. This shows that there exists an element $u \in E$ such that $J u=u^{*}$. It follows that

$$
\begin{aligned}
\phi\left(x_{n+1}, u_{n}\right) & =\left\|x_{n+1}\right\|^{2}-2\left\langle x_{n+1}, J u_{n}\right\rangle+\left\|u_{n}\right\|^{2} \\
& =\left\|x_{n+1}\right\|^{2}-2\left\langle x_{n+1}, J u_{n}\right\rangle+\left\|J u_{n}\right\|^{2} .
\end{aligned}
$$

Taking $\liminf _{n \rightarrow \infty}$ on the both sides of the equality above yields that

$$
\begin{aligned}
0 & \geq\|\bar{x}\|^{2}-2\left\langle\bar{x}, u^{*}\right\rangle+\left\|u^{*}\right\|^{2} \\
& =\|\bar{x}\|^{2}-2\langle\bar{x}, J u\rangle+\|J u\|^{2} \\
& =\|\bar{x}\|^{2}-2\langle\bar{x}, J u\rangle+\|u\|^{2} \\
& =\phi(\bar{x}, u) .
\end{aligned}
$$

That is, $\bar{x}=u$, which in turn implies that $u^{*}=J \bar{x}$. It follows that $J u_{n} \rightarrow J \bar{x} \in E^{*}$. Since $E^{*}$ enjoys the Kadec-Klee property, we obtain from (3.3) that $\lim _{n \rightarrow \infty} J u_{n}=J \bar{x}$. Since $J^{-1}$ : $E^{*} \rightarrow E$ is demi-continuous and $E$ enjoys the Kadec-Klee property, we obtain that $u_{n} \rightarrow \bar{x}$, as $n \rightarrow \infty$. Note that $\left\|x_{n}-u_{n}\right\| \leq\left\|x_{n}-\bar{x}\right\|+\left\|\bar{x}-u_{n}\right\|$. It follows that

$$
\lim _{n \rightarrow \infty}\left\|x_{n}-u_{n}\right\|=0
$$

Since $J$ is uniformly norm-to-norm continuous on any bounded sets, we have

$$
\lim _{n \rightarrow \infty}\left\|J x_{n}-J u_{n}\right\|=0
$$

On the other hand, we have

$$
\begin{aligned}
\phi\left(w, x_{n}\right)-\phi\left(w, u_{n}\right) & =\left\|x_{n}\right\|^{2}-\left\|u_{n}\right\|^{2}-2\left\langle w, J x_{n}-J u_{n}\right\rangle \\
& \leq\left\|x_{n}-u_{n}\right\|\left(\left\|x_{n}\right\|+\left\|u_{n}\right\|\right)+2\|w\|\left\|J x_{n}-J u_{n}\right\| .
\end{aligned}
$$

We, therefore, find that

$$
\lim _{n \rightarrow \infty}\left(\phi\left(w, x_{n}\right)-\phi\left(w, u_{n}\right)\right)=0 .
$$


Since $E$ is uniformly smooth, we know that $E^{*}$ is uniformly convex. In view of Lemma 2.10, we find that

$$
\begin{aligned}
\phi\left(w, u_{n}\right)= & \phi\left(w, K_{r_{n}} y_{n}\right) \\
\leq & \phi\left(w, y_{n}\right) \\
= & \phi\left(w, J^{-1}\left(\alpha_{n, 0} J x_{n}+\sum_{i=1}^{N} \alpha_{n, i} J T_{i}^{n} x_{n}\right)\right) \\
= & \|w\|^{2}-2\left\langle w, \alpha_{n, 0} J x_{n}+\sum_{i=1}^{N} \alpha_{n, i} J T_{i}^{n} x_{n}\right\rangle+\left\|\alpha_{n, 0} J x_{n}+\sum_{i=1}^{N} \alpha_{n, i} J T_{i}^{n} x_{n}\right\|^{2} \\
\leq & \|w\|^{2}-2 \alpha_{n, 0}\left\langle w, J x_{n}\right\rangle-2 \sum_{i=1}^{N} \alpha_{n, i}\left\langle w, J T_{i}^{n} x_{n}\right\rangle+\alpha_{n, 0}\left\|x_{n}\right\|^{2} \\
& +\sum_{i=1}^{N} \alpha_{n, i}\left\|T_{i}^{n} x_{n}\right\|^{2}-\alpha_{n, 0} \alpha_{n, 1} g\left(\left\|J x_{n}-J T_{1}^{n} x_{n}\right\|\right) \\
= & \alpha_{n, 0} \phi\left(w, x_{n}\right)+\sum_{i=1}^{N} \alpha_{n, i} \phi\left(w, T_{i}^{n} x_{n}\right)-\alpha_{n, 0} \alpha_{n, 1} g\left(\left\|J x_{n}-J T_{1}^{n} x_{n}\right\|\right) \\
\leq & \alpha_{n, 0} \phi\left(w, x_{n}\right)+\sum_{i=1}^{N} \alpha_{n, i} \phi\left(w, x_{n}\right)+\sum_{i=1}^{N} \alpha_{n, i} \xi_{n} \\
& -\alpha_{n, 0} \alpha_{n, 1} g\left(\left\|J x_{n}-J T_{1}^{n} x_{n}\right\|\right) \\
= & \phi\left(w, x_{n}\right)+\sum_{i=1}^{N} \alpha_{n, i} \xi_{n}-\alpha_{n, 0} \alpha_{n, 1} g\left(\left\|J x_{n}-J T_{1}^{n} x_{n}\right\|\right) \\
\leq & \phi\left(w, x_{n}\right)+N \xi_{n}-\alpha_{n, 0} \alpha_{n, 1} g\left(\left\|J x_{n}-J T_{1}^{n} x_{n}\right\|\right) . \\
&
\end{aligned}
$$

It follows that $\alpha_{n, 0} \alpha_{n, 1} g\left(\left\|J x_{n}-J T_{1}^{n} x_{n}\right\|\right) \leq \phi\left(w, x_{n}\right)-\phi\left(w, u_{n}\right)+\xi_{n}$. In view of the restriction on the sequences, we find from (3.6) that $\lim _{n \rightarrow \infty} g\left(\left\|J x_{n}-J T_{1}^{n} x_{n}\right\|\right)=0$. It follows that $\lim _{n \rightarrow \infty}\left\|J x_{n}-J T_{1}^{n} x_{n}\right\|=0$. In the same way, we obtain that $\lim _{n \rightarrow \infty}\left\|J x_{n}-J T_{i}^{n} x_{n}\right\|=$ $0, \forall 2 \leq i \leq N$. Notice that $\left\|J T_{i}^{n} x_{n}-J \bar{x}\right\| \leq\left\|J T_{i}^{n} x_{n}-J x_{n}\right\|+\left\|J x_{n}-J \bar{x}\right\|$. It follows that $\lim _{n \rightarrow \infty}\left\|J T_{i}^{n} x_{n}-J \bar{x}\right\|=0$. The demicontinuity of $J^{-1}: E^{*} \rightarrow E$ implies that $T_{i}^{n} x_{n} \rightarrow \bar{x}$. Note that

$$
\left|\left\|T_{i}^{n} x_{n}\right\|-\|\bar{x}\|\right|=\left|\left\|J T_{i}^{n} x_{n}\right\|-\|J \bar{x}\|\right| \leq\left\|J T_{i}^{n} x_{n}-J \bar{x}\right\| .
$$

This implies that $\lim _{n \rightarrow \infty}\left\|T_{i}^{n} x_{n}\right\|=\|\bar{x}\|$. Since $E$ has the Kadec-Klee property, we obtain that $\lim _{n \rightarrow \infty}\left\|T_{i}^{n} x_{n}-\bar{x}\right\|=0$. On the other hand, we have

$$
\left\|T_{i}^{n+1} x_{n}-\bar{x}\right\| \leq\left\|T_{i}^{n+1} x_{n}-T_{i}^{n} x_{n}\right\|+\left\|T_{i}^{n} x_{n}-\bar{x}\right\|
$$

It follows from the asymptotic regularity of $T_{i}$ that $\lim _{n \rightarrow \infty}\left\|T_{i}^{n+1} x_{n}-\bar{x}\right\|=0$. That is, $T_{i} T_{i}^{n} x_{n} \rightarrow \bar{x}$. From the closedness of $T_{i}$, we find $\bar{x}=T_{i} \bar{x}$ for every $1 \leq i \leq N$. This proves $\bar{x} \in \bigcap_{i=1}^{N} F\left(T_{i}\right)$. Now, we state that $\bar{x} \in E P(f, A)$. In view of Lemma 2.9, we find that

$$
\phi\left(u_{n}, y_{n}\right) \leq \phi\left(w, y_{n}\right)-\phi\left(w, u_{n}\right) \leq \phi\left(w, x_{n}\right)+N \xi_{n}-\phi\left(w, u_{n}\right) .
$$


It follows from (3.6) that $\lim _{n \rightarrow \infty} \phi\left(u_{n}, y_{n}\right)=0$. This implies that $\lim _{n \rightarrow \infty}\left(\left\|u_{n}\right\|-\left\|y_{n}\right\|\right)=0$. It follows from (3.4) that $\lim _{n \rightarrow \infty}\left\|y_{n}\right\|=\|\bar{x}\|$. It follows that

$$
\lim _{n \rightarrow \infty}\left\|J y_{n}\right\|=\lim _{n \rightarrow \infty}\left\|y_{n}\right\|=\|\bar{x}\|=\|J \bar{x}\| .
$$

This shows that $\left\{y y_{n}\right\}$ is bounded. Since $E^{*}$ is reflexive, we may assume that $J y_{n} \rightarrow y^{*} \in E^{*}$. In view of $J(E)=E^{*}$, we see that there exists $y \in E$ such that $J y=y^{*}$. It follows that $\phi\left(u_{n}, y_{n}\right)=$ $\left\|u_{n}\right\|^{2}-2\left\langle u_{n}, J y_{n}\right\rangle+\left\|J y_{n}\right\|^{2}$. Taking $\liminf _{n \rightarrow \infty}$ on the both sides of the equality above yields that

$$
\begin{aligned}
0 & \geq\|\bar{x}\|^{2}-2\left\langle\bar{x}, y^{*}\right\rangle+\left\|y^{*}\right\|^{2} \\
& =\|\bar{x}\|^{2}-2\langle\bar{x}, J y\rangle+\|J y\|^{2} \\
& =\|\bar{x}\|^{2}-2\langle\bar{x}, J y\rangle+\|y\|^{2} \\
& =\phi(\bar{x}, y) .
\end{aligned}
$$

That is, $\bar{x}=y$, which in turn implies that $y^{*}=J \bar{x}$. It follows that $J y_{n} \rightarrow J \bar{x} \in E^{*}$. Since $E^{*}$ enjoys the Kadec-Klee property, we obtain that $J y_{n}-J \bar{x} \rightarrow 0$ as $n \rightarrow \infty$. Note that $J^{-1}$ : $E^{*} \rightarrow E$ is demi-continuous. It follows that $y_{n} \rightarrow \bar{x}$. Since $E$ enjoys the Kadec-Klee property, we obtain that $y_{n} \rightarrow \bar{x}$ as $n \rightarrow \infty$. Note that $\left\|u_{n}-y_{n}\right\| \leq\left\|u_{n}-\bar{x}\right\|+\left\|\bar{x}-y_{n}\right\|$. This implies that $\lim _{n \rightarrow \infty}\left\|u_{n}-y_{n}\right\|=0$. Since $J$ is uniformly norm-to-norm continuous on any bounded sets, we have $\lim _{n \rightarrow \infty}\left\|J u_{n}-J y_{n}\right\|=0$. In view of the assumption $r_{n} \geq k$, we see that

$$
\lim _{n \rightarrow \infty} \frac{\left\|J u_{n}-J y_{n}\right\|}{r_{n}}=0
$$

Since $u_{n}=K_{r_{n}} y_{n}$, we find that

$$
F\left(u_{n}, y\right)+\frac{1}{r_{n}}\left\langle y-u_{n}, J u_{n}-J y_{n}\right\rangle \geq 0, \quad \forall y \in C,
$$

where $F\left(u_{n}, y\right)=f\left(u_{n}, y\right)+\left\langle A u_{n}+y-u_{n}\right\rangle$ for every $y \in C$. It follows from (A2) that

$$
\left\|y-u_{n}\right\| \frac{\left\|J u_{n}-J y_{n}\right\|}{r_{n}} \geq \frac{1}{r_{n}}\left\langle y-u_{n}, J u_{n}-J y_{n}\right\rangle \geq F\left(y, u_{n}\right), \quad \forall y \in C .
$$

It follows from (3.7) that

$$
F(y, \bar{x}) \leq 0, \quad \forall y \in C
$$

For $0<t<1$ and $y \in C$, define $y_{t}=t y+(1-t) \bar{x}$. It follows that $y_{t} \in C$, which yields that $F\left(y_{t}, \bar{x}\right) \leq 0$. It follows from (A1) and (A4) that

$$
0=F\left(y_{t}, y_{t}\right) \leq t F\left(y_{t}, y\right)+(1-t) F\left(y_{t}, \bar{x}\right) \leq t F\left(y_{t}, y\right) .
$$

That is,

$$
F\left(y_{t}, y\right) \geq 0 .
$$


Letting $t \downarrow 0$, we obtain from (A3) that $F(\bar{x}, y) \geq 0, \forall y \in C$. That is, $f\left(u_{n}, y\right)+\left\langle A u_{n}+y-\right.$ $\left.u_{n}\right\rangle \geq 0$ for every $y \in C$. This implies that $\bar{x} \in E P(f, A)$. This completes the proof that $\bar{x} \in$ $\bigcap_{i=1}^{N} F\left(T_{i}\right) \cap E P(f, A)$. Since $x_{n+1}=\Pi_{H_{n} \cap W_{n}} x_{0}$. In view of Lemma 2.7, we find that

$$
\left\langle x_{n+1}-w, J x_{0}-J x_{n+1}\right\rangle \geq 0, \quad w \in H_{n} \cap W_{n} .
$$

Since $\bigcap_{i=1}^{N} F\left(T_{i}\right) \cap E P(f, A) \subset H_{n} \cap W_{n}$, we arrive at

$$
\left\langle x_{n+1}-w, J x_{0}-J x_{n+1}\right\rangle \geq 0
$$

Letting $n \rightarrow \infty$ in the above inequality, we obtain that

$$
\left\langle\bar{x}-w, J x_{0}-J \bar{x}\right\rangle \geq 0, \quad \forall w \in \bigcap_{i=1}^{N} F\left(T_{i}\right) \cap E P(f, A) .
$$

It follows from Lemma 2.7 that $\bar{x}=\prod_{\bigcap_{i=1}^{N} F\left(T_{i}\right) \cap E P(f, A)} x_{0}$. This completes the proof.

Remark 3.2 Theorem 3.1 includes the corresponding results in the literature as special cases. Since every uniformly convex Banach space enjoys the Kadec-Klee property, the framework of the space can be applicable to $L^{p}, p \geq 1$.

Next, we state a result on Ky Fan inequality (2.4) and a single asymptotically quasi- $\phi$ nonexpansive mapping in the intermediate sense.

Corollary 3.3 Let E be a uniformly smooth and strictly convex Banach space which also enjoys the Kadec-Klee property, and let $C$ be a nonempty closed and convex subset of E. Let $f$ be a bifunction from $C \times C$ to $\mathbb{R}$ satisfying (A1)-(A4). Let $T: C \rightarrow C$ be an asymptotically quasi- $\phi$-nonexpansive mapping in the intermediate sense. Assume that $T$ is closed asymptotically regular on $C$ and $F(T) \cap E P(f)$ is nonempty and bounded. Let $\left\{x_{n}\right\}$ be a sequence generated in the following manner:

$$
\left\{\begin{array}{l}
x_{0} \in C \quad \text { chosen arbitrarily, } \\
y_{n}=J^{-1}\left(\alpha_{n} J x_{n}+\left(1-\alpha_{n}\right) J T^{n} x_{n}\right), \\
u_{n} \in C \text { such that } f\left(u_{n}, y\right)+\frac{1}{r_{n}}\left\langle y-u_{n}, J u_{n}-J y_{n}\right\rangle \geq 0, \quad \forall y \in C, \\
H_{n}=\left\{z \in C: \phi\left(z, u_{n}\right) \leq \phi\left(z, x_{n}\right)+N \xi_{n}\right\}, \\
W_{n}=\left\{z \in C:\left\langle x_{n}-z, J x_{0}-J x_{n}\right\rangle \geq 0\right\}, \\
x_{n+1}=\Pi_{H_{n} \cap W_{n}} x_{0},
\end{array}\right.
$$

where $\xi_{n}=\max \left\{0, \sup _{p \in F(T), x \in C}\left(\phi\left(p, T^{n} x\right)-\phi(p, x)\right)\right\},\left\{\alpha_{n}\right\}$ is a real number sequence in $(0,1)$, $\left\{r_{n}\right\}$ is a real number sequence in $[k, \infty)$, where $k$ is some positive real number. Assume that $\liminf _{n \rightarrow \infty} \alpha_{n}\left(1-\alpha_{n}\right)>0$. Then the sequence $\left\{x_{n}\right\}$ converges strongly to $\Pi_{F(T) \cap E P(f)} x_{0}$, where $\Pi_{F(T) \cap E P(f)}$ is the generalized projection from $E$ onto $F(T) \cap E P(f)$.

If the mapping $T$ is quasi- $\phi$-nonexpansive, we find from Corollary 3.3 the following. 
Corollary 3.4 Let E be a uniformly smooth and strictly convex Banach space which also enjoys the Kadec-Klee property, and let $C$ be a nonempty closed and convex subset of $E$. Let $f$ be a bifunction from $C \times C$ to $\mathbb{R}$ satisfying (A1)-(A4). Let $T: C \rightarrow C$ be a quasi$\phi$-nonexpansive mapping. Assume that $F(T) \cap E P(f)$ is nonempty. Let $\left\{x_{n}\right\}$ be a sequence generated in the following manner:

$$
\left\{\begin{array}{l}
x_{0} \in C \quad \text { chosen arbitrarily, } \\
y_{n}=J^{-1}\left(\alpha_{n} J x_{n}+\left(1-\alpha_{n}\right) J T x_{n}\right), \\
u_{n} \in C \text { such that } f\left(u_{n}, y\right)+\frac{1}{r_{n}}\left\langle y-u_{n}, J u_{n}-J y_{n}\right\rangle \geq 0, \quad \forall y \in C, \\
H_{n}=\left\{z \in C: \phi\left(z, u_{n}\right) \leq \phi\left(z, x_{n}\right)\right\}, \\
W_{n}=\left\{z \in C:\left\langle x_{n}-z, J x_{0}-J x_{n}\right\rangle \geq 0\right\}, \\
x_{n+1}=\Pi_{H_{n} \cap W_{n}} x_{0},
\end{array}\right.
$$

where $\left\{\alpha_{n}\right\}$ is a real number sequence in $(0,1),\left\{r_{n}\right\}$ is a real number sequence in $[k, \infty)$, where $k$ is some positive real number. Assume that $\liminf _{n \rightarrow \infty} \alpha_{n}\left(1-\alpha_{n}\right)>0$. Then the sequence $\left\{x_{n}\right\}$ converges strongly to $\Pi_{F(T) \cap E P(f)} x_{0}$, where $\Pi_{F(T) \cap E P(f)}$ is the generalized projection from $E$ onto $F(T) \cap E P(f)$.

Finally, we give a result in the framework of Hilbert spaces based on Theorem 3.1.

Corollary 3.5 Let E be a Hilbert space, and let $C$ be a nonempty closed and convex subset of $E$. Let $f$ be a bifunction from $C \times C$ to $\mathbb{R}$ satisfying (A1)-(A4), and let $N$ be some positive integer. Let $A: C \rightarrow E$ be a $\kappa_{i}$-inverse-strongly monotone mapping. Let $T_{i}: C \rightarrow C$ be an asymptotically quasi-nonexpansive mapping in the intermediate sense for every $1 \leq i \leq N$. Assume that $T_{i}$ is closed asymptotically regular on $C$ and $\bigcap_{i=1}^{N} F\left(T_{i}\right) \cap E P(f, A)$ is nonempty and bounded. Let $\left\{x_{n}\right\}$ be a sequence generated in the following manner:

$$
\left\{\begin{array}{l}
x_{0} \in C \quad \text { chosen arbitrarily, } \\
y_{n}=\alpha_{n, 0} x_{n}+\sum_{i=1}^{N} \alpha_{n, i} T_{i}^{n} x_{n}, \\
u_{n} \in C \text { such that } f\left(u_{n}, y\right)+\left\langle A u_{n}+y-u_{n}\right\rangle+\frac{1}{r_{n}}\left\langle y-u_{n}, u_{n}-y_{n}\right\rangle \geq 0, \quad \forall y \in C, \\
H_{n}=\left\{z \in C:\left\|z-u_{n}\right\|^{2} \leq\left\|z-x_{n}\right\|^{2}+N \xi_{n}\right\}, \\
W_{n}=\left\{z \in C:\left\langle x_{n}-z, x_{0}-x_{n}\right\rangle \geq 0\right\}, \\
x_{n+1}=\operatorname{Proj}_{H_{n} \cap W_{n}} x_{0},
\end{array}\right.
$$

where $\xi_{n}=\max \left\{0, \sup _{p \in \bigcap_{i=1}^{N} F\left(T_{i}\right), x \in C}\left(\left\|p-T_{i}^{n} x\right\|^{2}-\|p-x\|^{2}\right)\right\},\left\{\alpha_{n, i}\right\}$ is a real number sequence in $(0,1)$ for every $1 \leq i \leq N,\left\{r_{n}\right\}$ is a real number sequence in $[k, \infty)$, where $k$ is some positive real number. Assume that $\sum_{i=0}^{N} \alpha_{n, i}=1$ and $\liminf _{n \rightarrow \infty} \alpha_{n, 0} \alpha_{n, i}>0$ for every $1 \leq i \leq N$. Then

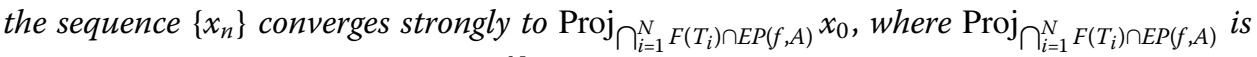
the metric projection from $E$ onto $\bigcap_{i=1}^{N} F\left(T_{i}\right) \cap E P(f, A)$.

Proof Since $\phi(x, y)=\|x-y\|^{2}$ and $J=I$ in the framework of Hilbert spaces, we draw the desired conclusion immediately. 
Authors' contributions

Both authors contributed equally to this manuscript. Both authors read and approved the final manuscript.

\section{Author details}

${ }^{1}$ Department of Mathematics, Hangzhou Normal University, Hangzhou, China. ${ }^{2}$ School of Mathematics and Information Science, Shangqiu Normal University, Shangqiu, 476000, China.

\section{Acknowledgements}

The authors are grateful to the two anonymous reviewers' suggestions which improved the contents of the article.

\section{Received: 9 September 2013 Accepted: 25 October 2013 Published: 21 Nov 2013}

\section{References}

1. Park, S: A review of the KKM theory on $\phi_{A}$-space or GFC-spaces. Adv. Fixed Point Theory 3, 355-382 (2013)

2. Cho, SY, Li, W, Kang, SM: Convergence analysis of an iterative algorithm for monotone operators. J. Inequal. Appl. 2013, $199(2013)$

3. Kim, JK: Strong convergence theorems by hybrid projection methods for equilibrium problems and fixed point problems of the asymptotically quasi- $\phi$-nonexpansive mappings. Fixed Point Theory Appl. 2011, 10 (2011)

4. Wang, ZM, Lou, W: A new iterative algorithm of common solutions to quasi-variational inclusion and fixed point problems. J. Math. Comput. Sci. 3, 57-72 (2013)

5. Wang, G, Sun, S: Hybrid projection algorithms for fixed point and equilibrium problems in a Banach space. Adv. Fixed Point Theory 3, 578-594 (2013)

6. Zegeye, $\mathrm{H}$, Shahzad, N: Strong convergence theorem for a common point of solution of variational inequality and fixed point problem. Adv. Fixed Point Theory 2, 374-397 (2012)

7. Cho, SY, Kang, SM: Approximation of fixed points of pseudocontraction semigroups based on a viscosity iterative process. Appl. Math. Lett. 24, 224-228 (2011)

8. Qin, X, Cho, SY, Kang, SM: Convergence of an iterative algorithm for systems of variational inequalities and nonexpansive mappings with applications. J. Comput. Appl. Math. 233, 231-240 (2009)

9. LV, S: Strong convergence of a general iterative algorithm in Hilbert spaces. J. Inequal. Appl. 2013, 19 (2013)

10. Yuan, Q: Some results on asymptotically quasi- $\boldsymbol{\phi}$-nonexpansive mappings in the intermediate sense. J. Fixed Point Theory 2012, 1 (2012)

11. Cho, SY, Qin, X, Kang, SM: Iterative processes for common fixed points of two different families of mappings with applications. J. Glob. Optim. (2013). doi:10.1007/s10898-012-0017-y

12. He, RH: Coincidence theorem and existence theorems of solutions for a system of Ky Fan type minimax inequalities in FC-spaces. Adv. Fixed Point Theory 2, 47-57 (2012)

13. Tanaka, Y: A constructive version of Ky Fan's coincidence theorem. J. Math. Comput. Sci. 2, 926-936 (2012)

14. Qin, X, Cho, SY, Kang, SM: An extragradient-type method for generalized equilibrium problems involving strictly pseudocontractive mappings. J. Glob. Optim. 49, 679-693 (2011)

15. Al-Bayati, AY, Al-Kawaz, RZ: A new hybrid WC-FR conjugate gradient-algorithm with modified secant condition for unconstrained optimization. J. Math. Comput. Sci. 2, 937-966 (2012)

16. Qin, X, Cho, SY, Kang, SM: Iterative algorithms for variational inequality and equilibrium problems with applications. J. Glob. Optim. 48, 423-445 (2010)

17. Chen, JH: Iterations for equilibrium and fixed point problems. J. Nonlinear Funct. Anal. 2013, 4 (2013)

18. Yang, S: A proximal point algorithm for zeros of monotone operators. Math. Finance Lett. 2013, 7 (2013)

19. Song, J, Chen, M: On generalized asymptotically quasi- $\boldsymbol{\phi}$-nonexpansive mappings and a Ky Fan inequality. Fixed Point Theory Appl. 2013, 237 (2013)

20. Cho, SY, Kang, SM: Approximation of common solutions of variational inequalities via strict pseudocontractions. Acta Math. Sci. 32, 1607-1618 (2012)

21. Takahashi, W, Yao, JC: Nonlinear operators of monotone type and convergence theorems with equilibrium problems in Banach spaces. Taiwan. J. Math. 15, 787-818 (2011)

22. Takahashi, W, Wong, NC, Yao, JC: Iterative common solutions for monotone inclusion problems, fixed point problems and equilibrium problems. Fixed Point Theory Appl. 2012, 181 (2012)

23. Noor, MA, Noor, Kl, Waseem, M: Decomposition method for solving system of linear equations. Eng. Math. Lett. 2 , 34-41 (2013)

24. Qing, Y, Kim, JK: Weak convergence of algorithms for asymptotically strict pseudocontractions in the intermediate sense and equilibrium problems. Fixed Point Theory Appl. 2012, 132 (2012)

25. Kim, JK: A new iterative algorithm of pseudomonotone mappings for equilibrium problems in Hilbert spaces. J. Inequal. Appl. 2013, 128 (2013)

26. Kang, SM, Cho, SY, Liu, Z: Convergence of iterative sequences for generalized equilibrium problems involving inverse-strongly monotone mappings. J. Inequal. Appl. 2010, 827082 (2010)

27. Wu, C: Mann iteration for zero theorems of accretive operators. J. Fixed Point Theory 2013, 3 (2013)

28. Showalter, RE: Monotone Operators in Banach Space and Nonlinear Partial Differential Equations. Math. Surveys Monogr., vol. 49. Am. Math. Soc., Providence (1997)

29. Alber, Yl: Metric and generalized projection operators in Banach spaces: properties and applications. In: Kartsatos, AG (ed.) Theory and Applications of Nonlinear Operators of Accretive and Monotone Type. Dekker, New York (1996)

30. Agarwal, RP, Cho, YJ, Qin, X: Generalized projection algorithms for nonlinear operators. Numer. Funct. Anal. Optim. 28, 1197-1215 (2007)

31. Qin, X, Cho, YJ, Kang, SM: Convergence theorems of common elements for equilibrium problems and fixed point problems in Banach spaces. J. Comput. Appl. Math. 225, 20-30 (2009)

32. Zhou, H, Gao, G, Tan, B: Convergence theorems of a modified hybrid algorithm for a family of quasi- $\phi$-asymptotically nonexpansive mappings. J. Appl. Math. Comput. 32, 453-464 (2010)

33. Qin, X, Cho, SY, Kang, SM: On hybrid projection methods for asymptotically quasi- $\boldsymbol{\phi}$-nonexpansive mappings. Appl. Math. Comput. 215, 3874-3883 (2010) 
34. Qin, X, Wang, L: On asymptotically quasi- $\phi$-nonexpansive mappings in the intermediate sense. Abstr. Appl. Anal. 2012, $636217(2012)$

35. Hecai, Y, Aichao, L: Projection algorithms for treating asymptotically quasi- $\phi$-nonexpansive mappings in the intermediate sense. J. Inequal. Appl. 2013, 265 (2013)

36. Kirk, WA: Fixed point theorems for non-Lipschitzian mappings of asymptotically nonexpansive type. Isr. J. Math. 17, 339-346 (1974)

37. Chang, SS, Chan, CK, Lee, HWJ: A new hybrid method for solving a generalized equilibrium problem, solving a variational inequality problem and obtaining common fixed points in Banach spaces, with applications. Nonlinear Anal. 73, 2260-2270 (2010)

38. Zǎlinescu, C: On uniformly convex functions. J. Math. Anal. Appl. 95, 344-374 (1983)

10.1186/1687-1812-2013-305

Cite this article as: Qing and Lv: A strong convergence theorem for solutions of equilibrium problems and asymptotically quasi- $\phi$-nonexpansive mappings in the intermediate sense. Fixed Point Theory and Applications 2013, 2013:305

Submit your manuscript to a SpringerOpen ${ }^{\circ}$ journal and benefit from:

- Convenient online submission

- Rigorous peer review

- Immediate publication on acceptance

- Open access: articles freely available online

- High visibility within the field

- Retaining the copyright to your article

Submit your next manuscript at $>$ springeropen.com 